\title{
Los hermanos Durini y las Casas de Corrección en Costa Rica
}

\section{Leonardo Santamaría Montero' Mauricio Oviedo Salazar²}

Recepción: 4 de mayo de 2015 / Aprobación: 3 de agosto de 2015

\section{Resumen}

Este trabajo se concentra en la inmigración de italianos y su relación con el proceso de modernización que experimentó el paisaje arquitectónico de la ciudad de San José, capital de Costa Rica, desde finales de siglo XIX hasta los primeros años delXX. Para ello, se estudiará la vida y obra de los hermanos suizo-italianos Francesco y Lorenzo Durini Vasalli. La contribución arquitectónico-cultural de los Durini es comentada a partir del análisis delas Casas de Corrección(1897-1902). Paralainvestigación seconsultaronfuentes primarias y secundarias, las cuales fueron comparadas y analizadas bajo el método hipotético-deductivo. Mediante el análisis de las Casas de Corrección podemos corroborar la importancia que tuvieron los hermanos Durini para la transformación del paisaje urbano josefino.

\section{Palabras clave}

Arte costarricense; siglo XIX; Historia de la cultura; Historia de la arquitectura; Italia

\section{Abstract}

This work focuses on immigration of Italians and their relationship with the modernization process of the architectural landscape in Costa Rica's capital city San José since the late nineteenth to the early twentieth centuries. The article examines the life and work of the Swiss-Italian brothers Francesco and Lorenzo Durini Vasalli, and discusses the architectural and cultural contribution of Durini based on the analysis of the project of Houses of Correction (1897-1902). For research, primary and secondary sources were consulted, which were compared and analyzed under the hypothetical-deductive method. By analyzing the Houses of Correction project the article confirms the importance of Durini brothers in the transformation of the urban landscape of San José.

\section{Key words}

Costa Rican art; Nineteenth Century; History of culture; History of architecture; Italy

1 Costarricense. Bachiller en Historia del Arte por la Universidad de Costa Rica (UCR). Investigador del Instituto de Investigaciones en Arte (IIArte) en la misma institución. Correo electrónico: leonardo.santamaria@ucr.ac.cr

2 Costarricense. Licenciado en Historia del Arte por la UCR. Investigador del IIArte en la misma institución. Correo electrónico: mauricio.oviedo.salazar@gmail.com 


\section{Resumo}

Este artigo estuda na imigração italiana e sua relação com o processo de modernização experimentado pela paisagem arquitetônica de São José, a partir do final do século XIX para o XX. Para fazer isso, a vida ea obra dos irmãos suíço-italiana, Francesco y Lorenzo, Durini Vasalli ser estudado. A contribuição arquitetônica e cultural de Durini é discutido com base na análise das Casas de Correção (1897-1902). Para a pesquisa, fontes primárias e secundárias foram consultados, os quais foram comparados e analisados sob o método hipotético-dedutivo. Ao analisar as casas de correção Podemos confirmar a importância que tiveram os irmãos Durini para transformar a paisagem urbana de San Jose. Este artigo estuda na imigração italiana e sua relação com o processo de modernização experimentado pela paisagem arquitetônica de São José, a partir do final do século XIX para o XX.

\section{Palavras chave}

Arte costarriquense; Século XIX; História cultural; História da arquitetura; Itália

\section{Introducción}

Las migraciones culturales son la condición de emergencia de las culturas. De manera aún más decisiva, ponen en marcha transformaciones e innovaciones, pues los movimientos y los contactos entre culturas y lenguas favorecen las interrelaciones y dan lugar a otras percepciones espacio-temporales y en ocasiones incluso a otras prácticas sociales (Borsò, Temelli \& Viseneber, 2012, p. 15).

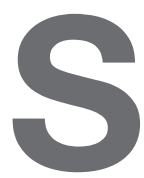
i bien la presente investigación no pretende problematizar en torno al concepto de migraciones culturales, consideramos oportuno iniciar con la cita textual arriba indicada, pues este estudio analizará las consecuencias artístico-culturales de la migración de personas pertenecientes a determinada cultura, quienes se asentaron en un país con una cultura esencialmente distinta. En efecto, nuestro caso de estudio corresponde a un proceso artístico-cultural desarrollado a partir de migraciones italianas que cotribuyó en parte ${ }^{3}$ a la renovación arquitectónica del paisaje josefino.

Durante el último cuarto del siglo XIX hubo, tanto en el Reino de Italia como en la República de Costa Rica, una serie de condiciones económicas y políticas que propiciaron un alto flujo migratorio desde dicho reino europeo hacia la novel república centroamericana. Tales factores socioeconómicos fueron expuestos en un trabajo reciente (Oviedo \& Santamaría, 2015, pp. 9-14), donde se establecieron las circunstancias que mediaron la llegada a Costa Rica de un grupo de comerciantes italianos que estuvieron vinculados con la construcción del Teatro Nacional (1891-1897) de dicho país. 
En este estudio, nuestro interés en las migraciones se centra en su impacto cultural con respecto al proceso de modernización que experimentó el paisaje arquitectónico josefino desde finales del siglo XIX y durante los primeros años del XX (Quesada, 2007). Para contextualizar los antecedentes de este proceso, en la primera parte se presentará un panorama de las condiciones socioeconómicas experimentadas en el Reino de Italia durante nuestro período de estudio; ulteriormente se estudiarán las políticas costarricenses de la época relativas a la inmigración; por último, nos concentraremos en los hermanos suizo-italianos Durini Vasalli, su llegada a Costa Rica y su incorporación al mercado artístico-arquitectónico del país. Una vez claro el modo de inserción y establecimiento de estas figuras en el país, nos dispondremos en la segunda parte a analizar las Casas de Corrección, edificios atribuidos principalmente a Lorenzo Durini, los cuales nos servirán de ejemplo para exponer la importancia que tuvo esta migración en particular en el proceso de modificación del paisaje urbano, vinculado al programa político que el país pretendía alcanzar.

\section{Del Tesino a San José: Ios Durini y las migraciones culturales decimonónicas}

Hasta la segunda mitad del siglo XIX las zonas geográficas que constituyen la Italia contemporánea no habían estado integradas en una misma unidad política (Kirk, 2005, p. 11; Hobsbawn, 2010, pp. 99-100). Tal unificación del territorio italiano fue gestada a partir de varias revoluciones iniciadas desde inicios de dicho siglo, pero que se articularon en movimientos políticos mayores en torno a 1848 (Hobsbawn, 2010, pp. 96-97). Tras años de luchas, Vittorio Emanuele II (1820-1878) finalmente logró unificar a gran parte del territorio italiano bajo un reino, proclamándose en 1861 primer monarca del mismo. Ahora bien, aunque el proceso de unificación de Italia respondió a diversos factores, entre ellos un movimiento eminentemente nacionalista ${ }^{4}$, por ahora solo analizaremos las condiciones político-económicas que mediaron la unificación del reino y las consecuencias sociales del nuevo modelo económico italiano.

Paralelo al proceso de unificación de Italia, la fuerza industrial y comercial europea apostó por el liberalismo como la vía para procurar un vasto desarrollo económico (Hobsbawn, 2010, p. 93). Sin embargo, el modelo liberal demostró, a partir de la década de 1870, una serie de fallas conocidas como la Gran Depresión de 1873-1896, la cual afectó la economía de la población europea (Hobsbawn, 2010, p. 58). En dicha coyuntura económica y considerando la inestable situación sociopolítica de una Italia unificada mediante la fuerza militar, una gran porción de la población emigró para buscar mejores condiciones de vida (Bariatti, 2001, pp. 17-20).

$4 \quad$ Para un análisis de las implicaciones arquitectónicas del Risorgimento y la unificación del Reino de Italia, consultar "Restoration and Romanticism, 1815-1860" y "Unification and the Nation's Capitals, 1860-1900", en The Architecture of Modern Italy (2005), del académico Terry Kirk. 
En la década de 1880 la emigración comenzaba a ser una realidad en Italia y las autoridades planteaban la necesidad de proteger al emigrante. Así lo demuestra una Circular del 6 de enero de 1883 del Departamento Real del Interior, en la cual se señalaba que era deber del gobierno velar por los intereses de los emigrantes sometidos a promesas falaces y abandonados en condiciones miserables en regiones lejanas y que, por lo tanto, quien quisiera enrolar emigrantes para países no europeos necesitaba obtener el consentimiento del Ministerio del Interior ${ }^{5}$ (Bariatti, 2001, p. 41).

Con respecto a las relaciones diplomáticas entre el Reino de Italia y la República de Costa Rica, el vínculo entre ambas unidades políticas se remonta a la administración (1849-1860) de Juan Rafael Mora Porras (1814-1860). El presidente Mora remitió una carta en 1853 precisamente a Vittore Emanuele II, entonces rey de Cerdeña, para establecer "negociaciones amistosas" entre ambas unidades políticas; "Ocho años después, llegó de Italia una comunicación oficial para el Presidente de la República de Costa Rica, en la cual se informaba que 'Su Majestad Víctor Manuel II... con regocijo general de los pueblos italianos y unánime votación del Parlamento Nacional, ha asumido... el título de Rey de Italia'" (Bariatti, 2001, pp. 43-44). En cuanto el gobierno costarricense recibió la noticia, se nombró a Louis Othon de Schroter como cónsul de Italia en Costa Rica y un año después se designó a Carlos Balestrina como cónsul de Costa Rica en la ciudad italiana de Génova (Bariatti, 2001, p. 44). Consecuentemente, las migraciones entre Italia y Costa Rica se dieron, desde el último cuarto del siglo XIX hasta mediados del siglo $X^{6}{ }^{6}$, mediadas por una relación amistosa entre ambas naciones.

Una vez expuestas las condiciones socioeconómicas que potenciaron la emigración de italianos y tras señalar los antecedentes diplomáticos entre Italia y Costa Rica, en las siguientes líneas identificaremos las políticas costarricenses que promovieron la inmigración de europeos durante el período acá estudiado.

Los países europeos sufren plétora de población, y la masa laboriosa de sus campos estrechos y esquilmados busca, como Colón, tierra en este viaje de la vida. Falta suelo y sobran brazos: es preciso descubrir nuevas tierras.

A millares salen los emigrantes del norte del viejo continente, y cada hombre lleva en su cerebro un caudal de ideas y en sus manos una suma de fuerza, para poner al servicio de los países nuevos y despoblados (La inmigración, 1890, 24 de abril).

Si bien en la sociedad costarricense coexistían diversas corrientes de pensamiento, los círculos intelectuales y los gobernantes, posteriores a la dicta-

5 Teóricamente, el estudio de las migraciones se divide en internas, o sea, dentro de los límites territoriales de un Estado, y externas, es decir, a nivel internacional; evidentemente nuestro caso de estudio corresponde a la segunda clase (Bariatti, 2001, p. 13). ciones entre Costa Rica y la Italia fascista (2001, p. 45). 
dura (1870-1882) del general Tomás Guardia Gutiérrez (1831-1882), estaban imbuidos en una versión latinoamericana del positivismo comtiano (Oviedo \& Santamaría, 2015, pp. 5-9), ideología que, a grandes rasgos, teorizaba tres grados de cultura, en los cuales se ubicaba a la cultura europea a la cabeza, como ejemplo de la ideal civilización progresista, moral e industrial. Por ello, no es de extrañar el surgimiento en Costa Rica de numerosas iniciativas, públicas y privadas, que pretendían aumentar la inmigración europea a suelo centroamericano. Ahora bien, es importante subrayar que la inmigración ansiada era estrictamente europea (de ningún otro continente o región en particular). Este interés por poblar Costa Rica con europeos, entre ellos los italianos, respondió principalmente a tres motivos: el pensamiento positivo consideraba a la cultura europea un ideal de civilización, por ello hubo un ferviente deseo de importar artistas e intelectuales provenientes de Europa; como lo evidencia el texto arriba citado, en Costa Rica se conocía la complicada situación sociopolítica de varios países europeos y las enormes oleadas migratorias dirigidas hacia América; la mano de obra europea era apetecida debido a su nivel de especialización con respecto a la construcción de ferrocarriles o edificios públicos (Bariatti, 2001, p. 20).

Estos deseos se vieron traducidos en políticas públicas que articularon las condiciones para que el país recibiera un alto número de inmigrantes europeos. Esto se ejemplifica mediante la revisión de leyes y decretos firmados durante el período acá estudiado, donde se evidencian los esfuerzos del gobierno para aumentar la llegada y asentamiento de determinado tipo de inmigrantes. Además, al consultar las memorias anuales correspondientes a la Secretaría de Fomento publicadas durante la década de 1890, se encuentra una sección dedicada a la situación relativa a la inmigración y las colonias extranjeras en territorio costarricense?.

Asimismo, tanto en editoriales de diarios como en publicaciones de líderes de opinión, la inmigración fue catalogada como una "de las más positivas esperanzas de regeneración y mejora de las condiciones sociales y económicas en que vivimos" (Inmigración, 1886, 6 de febrero). Al igual que el texto líneas antes citado, correspondiente al número de La Prensa Libre del 24 de abril de 1890, encontramos una publicación cuatro años anterior, donde el articulista argumentó de la siguiente manera por qué Costa Rica debía propiciar la inmigración:

¿De qué manera se puede implantar agricultura, industria y nuevos ramos de comercio? Haciendo que vengan inmigrantes que exploten en diversas formas el suelo y sus riquezas naturales y artificiales; inmigrantes que creen necesidades y los medios de satisfacerlas. Las concesiones que se hagan á este respecto no

$7 \quad$ Por ejemplo, en un contrato celebrado el 17 de abril de 1894 entre el Gobierno de la República y el sueco Carlos Berggren, este ciudadano europeo se comprometía a colonizar un sector de San Carlos, nombrado por el estado como Nueva Suecia. En su contrato, Berggren se había comprometido a poblar esta colonia con 100 inmigrantes provenientes de determinados lugares, su labor debía cumplirse antes del 25 de diciembre de 1895 (Ulloa, 1895). 
son concesiones; son pago ínfimo de un gran beneficio para el país (Inmigración, 1886, 6 de febrero).

Con este panorama costarricense respecto de la inmigración, un Reino de Italia con zonas empobrecidas y bajo cordiales relaciones diplomáticas entre ambas naciones, la emigración de italianos a Costa Rica se acrecentó durante la década de 1880 (Bariatti, 2001, pp. 71-108) ${ }^{8}$. Por ejemplo, entre las migraciones del último cuarto de siglo XIX destaca la llegada al país de Matteo Albertazzi (¿1830?-1887), piamontés que arribó a Costa Rica en agosto de 1885 junto con su hijo Constantino (Bariatti, 2001, p. 47). Inicialmente, Matteo y Constantino se abocaron a trabajar en la construcción del ferrocarril al Atlántico y a la agricultura; además, los Albertazzi gozaron de fama en San José y Cartago por su maestría en la cantería y la albañilería (Bariatti, 2001, pp. 45-47) ${ }^{9}$. Italia contaba con una tradición constructiva en la cual la cantería había jugado un rol crucial desde la Antigüedad hasta el siglo XIX; por ello, la incorporación de los Albertazzi, P. Maranini, Marcelino Vaglio, Pio Lazzari Andreoli y Natalio Borgia (Bariatti, pp. 120-122), al estrecho escenario de la construcción costarricense finisecular, representó la profesionalización de la cantería en el país.

De manera semejante, durante las décadas de 1880 y 1890 Costa Rica recibió a dos profesionales de la construcción de nacionalidad italiana, cuyo aporte fue fundamental para las transformaciones arquitectónicas del paisaje josefino: el ingeniero Enrique Invernizio Olivieri y el arquitecto Francisco Tenca Petrazzini (1860-1908) ${ }^{10}$. El primero trabajó para la Dirección General de Obras Públicas mediante licitaciones y como ingeniero oficial, por lo cual sus diseños contribuyeron al desarrollo de numerosas obras públicas. En el caso de Tenca, dicho arquitecto milanés llegó al país en 1896 y se insertó en el mercado de construcciones local (González, 1921, p. 287; Fernández, 2013, p. 43). Estilísticamente, Invernizio participó en obras caracterizadas por lenguajes académicos e inspiración historicista. Aunque Tenca trabajó en construcciones diseñadas según la tendencia académico-historicista de la época, su obra arquitectónica más reconocida corresponde a los edificios concebidos desde el modernismo italiano (stile Liberty), como el Almacén Steinvorth, entre otros.

No obstante, acá debe señalarse que la inmigración de italianos no fue mediada necesariamente por los gobiernos de ambas naciones, ni siquiera fue siempre directa desde Europa hacia suelo costarricense, sino que la situación era más compleja. Es decir, en un contexto en el cual cientos de euro-

$8 \quad$ Para un análisis general de las migraciones de italianos a Costa Rica, consultar Italianos en Costa Rica 1502-1952: de Cristóbal Colón a San Vito de Java (2001), de la historiadora italo-costarricense Rita Bariatti. Además, puede consultarse el catálogo de la exposición /l nuovo mondo. La influencia cultural de los italianos en América (Velázquez, Payne, Ungaro \& Meléndez, 2012), exhibición realizada en el Museo Nacional de Costa Rica y organizada por la Embajada de Italia en Costa Rica.

9 Consultar Memorias de un inmigrante italiano: Constantino Albertazzi Albertazzi (2006), edición, a cargo de Gabriela Echandi Albertazzi, del diario de Constantino Albertazzi.

10 Del que hablaremos brevemente en la segunda parte de este artículo. 
peos migraban dentro del continente europeo y hacia América en búsqueda de mejores condiciones de vida, los movimientos demográficos no eran unidireccionales, sino parte de rutas migratorias y respondían en gran medida a las oportunidades ofrecidas por cada nación. En consecuencia, los países americanos experimentaron durante el último cuarto del siglo XIX un alto índice de inmigración y emigración de extranjeros. Precisamente, la familia de artistas suizo-italianos ${ }^{11}$ de cuyo caso nos ocuparemos a continuación, corresponde a un ejemplo de migraciones múltiples.

Producto de su participación en las revueltas del Risorgimento ${ }^{12}$, el lombardo Giovanni Durini emigró de su tierra natal para establecerse en la ciudad suiza de Tremona (Capello, 2012, p. 122). Si bien Tremona pertenece a la región suiza del Tesino, estas poblaciones son herederas de la cultura italiana norteña, ya que Tesino, producto de un antecedente político-bélico, limita con el territorio italiano en sus fronteras occidental, sur y oriental (Hughes, 2006) ${ }^{13}$. Allí Giovanni se estableció y ejerció el oficio de escultor; asimismo, conoció a Elizabetta Vasalli, su futura esposa y madre de dos hijos: Lorenzo (1855-1906) y Francesco Antonio (1856-1920) Durini Vasalli (Imágenes 1 y 2) (Capello, 2012, p. 122).

Posterior al nacimiento de sus hijos, Giovanni y Elizabetta decidieron abandonar Tremona para buscar mejores condiciones socioeconómicas en la suramericana ciudad de Lima. Una vez establecidos en Perú, Giovanni ahorró dinero suficiente para enviar a sus hijos a estudiar artes en Génova, esto para que acabaran su formación y así pudiesen volver a Lima a colaborar en el negocio familiar (Capello, 2012, p. 122). Una vez de regreso en América, Lorenzo contrajo matrimonio con la limeña Juana Cáceres, con quien llegaría a tener dos hijos y una hija: Francisco Manuel (1880-1970), Pedro (1882-1912) y Gemma Durini Cáceres (1889-i?). No obstante, antes del nacimiento de Francisco Manuel, el matrimonio Durini Cáceres se asentó en Tremona hacia finales de la década de 1870, donde Lorenzo se dedicó a la producción y comercio de esculturas (Capello, 2012, p. 122).

Acerca de Francesco es poco lo que sabe tras su regreso a Lima durante la década de 1870. El decenio siguiente, en cambio, es de gran importancia

11 Cabe mencionar que los hermanos Durini Vasalli no fueron los únicos suizo-italianos. Por ejemplo, se encuentra el caso de los hermanos Induni Ferrari, procedentes del Tesino, quienes realizaron labores manuales en el país, lo cual los posicionó en el escenario artístico-constructivo josefino. Los aportes de los Induni a la renovación arquitectónica de la capital radicaron principalmente en la producción de ornamentación (relieves y esculturas de bulto) para edificios públicos y privados (Alvarado \& Alvarado, 2008, pp. 113-188). Para ahondar en la historia de la familia Induni, se recomienda la consulta de Los Induni: orígenes de una familia de emigrantes suizos y su contribución a la imaginería, ornamentación y arquitectura en Costa Rica y Panamá (1908-2008) (2008).

12 La unificación de Italia también es conocida como el Resurgimiento.

13 Debe señalarse que históricamente los habitantes del cantón del Tesino han sido italohablantes. Si bien este territorio políticamente pertenecía a la Confederación Helvética (Hughes, 2006), la tradición cultural italiana pervivía en la región habitada por el joven Giovanni. 

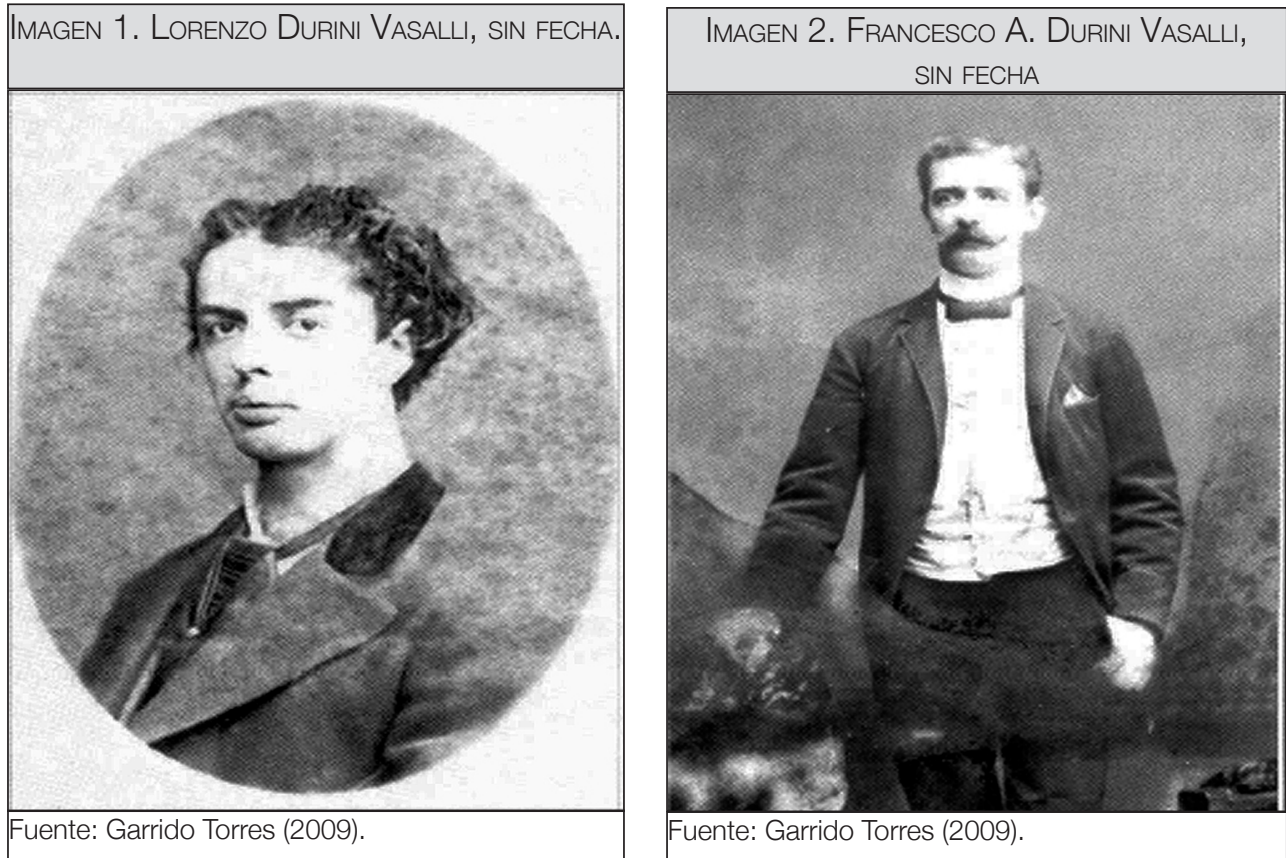

para la presente investigación, pues fue a comienzos de ella cuando Francesco Durini Vasalli llegó a Centroamérica. En el norte del istmo, Francesco se dedicó al comercio de esculturas de mármol y bronce, las cuales eran importadas desde Europa y le valieron a Durini un considerable éxito en el mercado artístico centroamericano (Cifuentes, 2013; Valdés, 2010; Del Pino, 2012; González, 2006; Gutiérrez, 1997; Torrejón, 1997; Fischel, 1992). En cuanto a Lorenzo, Capello lo describe como un escultor maduro, quien elaboró piezas pero que se destacó por la articulación de un mercado artístico entre el istmo, Génova y Suiza (2012, p. 122) ${ }^{14}$. De este modo, los hermanos Durini Vasalli articularon una red internacional de comercio artístico con un representante a cada lado del océano Atlántico.

Gracias a un anuncio publicado el 16 de noviembre de 1883, en el diario oficial La Gaceta, sabemos que Francesco estuvo en Costa Rica durante dos meses (aproximadamente mediados de noviembre hasta mediados de enero de 1884), hospedado en casa del doctor Juan Padilla, promocionándose ante el público en calidad de escultor y negociante de mármoles ${ }^{15}$. Tres años después, encontramos en los números del 19 y 26 de enero de Otro Diario, el siguiente anuncio, con el título Francisco A. Durini:

14 "Once this system was established enough to work independently, he [Lorenzo] moved to Costa Rica" [Una vez que este sistema fue establecido al punto de trabajar de forma independiente, él [Lorenzo] se trasladó a Costa Rica] (Capello, 2012, p. 122).

15 Contrario a lo expuesto por Omar García de Benedictis, descendiente directo de Gemma Durini Cáceres, hija de Lorenzo Durini Vasalli, el cuál fue citado por Fischel (1992, pp. 97-100), quien dice que Francesco llegó al país en 1886. 


\section{Francisco A. Durini ${ }^{16}$.}

\section{Escultor $^{17}$}

y negociante en mármoles, con depósito en Génova se encarga de hacer venir directamente de Italia, á precios sin competencia en Centro-América, monumentos, mausoleos, altares, púlpitos, cruzes [sic], lápidas, pilas bautismales y para agua bendita, estatuas, fuentes, macetas, escalones, ladrillos, tablas para muebles y mesa de café, etc. etc. ${ }^{18}$

A toda persona interesada le proporcionará modelos y planos de buen gusto artístico conforme á cuales se comprometerá hacer venír [sic] toda obra que se le encomiende, garantizando el trabajo y respondiendo de toda avería, hasta dejarla colocada en el lugar que se le designe.

Testimonio de sus trabajos son los dos grandes monumentos y un mausoleo erijidos [sic] á la memoria del General Morazán en las capitales del Salvador y Honduras, así como también los del sabio Valle, Doctor Reyes, General Cabañas en Tegucigalpa y muchos otros mausoleos de familia colocados en aquellas Repúblicas y en la de Nicaragua.

En trabajos, precios y condiciones, sin competencia.

Mediante este anuncio, Francesco Durini se presentó ante una nueva comunidad de posibles compradores y socios comerciales. Además de enumerar los objetos que importaba desde Europa, Francesco anotó una suerte de currículo con algunas de las obras hasta entonces vendidas en Centroamérica, donde destacan los mausoleos, por su carácter de encargos privados, y los monumentos comprados por los gobiernos de cada república mencionada. De modo semejante, tenemos evidencia de la venta en Costa Rica de dos obras, un mausoleo y un monumento. En primer lugar, el mausoleo de Francisco Echeverría y Alvarado (1830-1885), en el cual se encuentra la inscripción "Francisco A. DuRINI 1886"19. Por otro lado, Durini participó en la construcción del monumento al general Próspero Fernández Oreamuno (1834-1885)20.

Durante la segunda mitad de la década de 1880, siempre asociado comercialmente con su hermano Lorenzo, Francesco fortaleció sus negocios en Costa Rica y los demás países de Centroamérica. El 23 de mayo de 1889, con el calificativo de "Escultor Arquitecto y negociante en mármoles", Francesco publicó en La República un aviso comercial titulado "Progreso. Economía. Arte", en el cual anunciaba:

16 Desde su llegada a Lima, Francesco castellanizó su nombre a Francisco; del mismo modo, su padre Giovanni fue conocido en Perú como Juan Durini.

17 El destacado es del original.

18 Las itálicas son del documento original.

19 Dicho mausoleo se encuentra en el Cementerio General de San José.

20 En el número del 29 de enero de 1886 de Otro Diario, se notificó: "Bienvenidos sean, dirá nuestro amigo Don Francisco Durini al recibir el premio de cien pesos, ganados en el concurso que promovió el Gobierno para que se presentaran modelos del pedestal del monumento decretado para honrar la memoria del Gral. Fernández; la adjudicación de dicho premio se le ha hecho por el ministerio correspondiente y de acuerdo con el voto del Director General de Obras Públicas" (p. 2). 
Deseando contribuir en las mejoras y ornamentación de esta Capital, en lo que concierne á edificios públicos y privados, plazas, jardines, etc., he hecho arreglos con algunas de las principales fábricas Europeas de trabajos en cimento romano, zinc, hierro galvanizado, fundido y forjado, cartón Pierre ó papel maché, terracotta, decalcomania, vidrios floreados y de colores etc, para toda clase de construcción, y aviso á las personas interesadas, amantes del arte moderno ${ }^{21}$, que puedo hacerme cargo de la edificación de cualesquiera obra de arquitectura á precios sumamente baratos y sin competencia relativamente á las ventajas de seguridad y elegancia artística que estos presenten.

Entre pocos días abriré en esta Capital una galería artística de obras de esta materia como de terra-cota, cimiento etc. (Progreso. Economía. Arte, 23 de mayo, 1889, p. 1).

Así, tres años después de su presentación en el país como escultor y negociante de mármoles, Francesco ya ofertaba sus servicios como arquitecto y constructor como se aprecia en el anuncio citado anteriormente, para entonces, se estima que llegó a Costa Rica su hermano Lorenzo junto con su familia ${ }^{22}$. Consideramos que el aviso coincide con su arribo, ya que además de comerciante y escultor, la obra de Lorenzo también se caracterizó por la producción arquitectónica, tanto independiente como en asociación con Francesco. "There [Costa Rica], the brothers formed a new firm named Durini Hermanos $^{23}$, whose rapid turnaround of high-quality efforts garnered them a local reputation, particularly among Lorenzo's contacts in freemasonry circles" [Allí, los hermanos formaron una nueva empresa llamada Durini Hermanos, cuyo rápido cambio en cuanto a esfuerzos de alta calidad les dio una reputación local, particularmente entre los contactos de Lorenzo en los círculos de francmasonería] (Capello, 2012, p. 122). Una vez con Lorenzo instalado en San José, Francesco se mantuvo por más tiempo en Guatemala, lugar donde se ubicaba su residencia oficial.

Ahora con Lorenzo en San José, Francesco en Guatemala y en coordinación con sus contactos comerciales en Europa, los hermanos Durini Vasalli produjeron en Costa Rica una vasta cantidad de obras, públicas y privadas, durante la década de 1890 e inicios de siglo XX. Sin duda, debe resaltarse la participación de Durini Hermanos en la construcción del Teatro Nacional de Costa Rica (1891-1897), epítome de su labor artístico-comercial en este país,

21 Por moderno Durini no se refería a una corriente modernista, sino a un estilo academicista e historicista, el cual había sido vinculado internacionalmente con una determinada noción de modernización arquitectónica aplicada a los Estados decimonónicos liberales.

22 "His two children, Francisco Manuel and Pedro, were born in the old country but would spend their formative years in Costa Rica" [Sus dos hijos, Francisco Manuel y Pedro, nacieron en el viejo país pero pasaron sus años de formación en Costa Rica] (Capello, 2012, p. 122). En efecto, los Durini Cáceres estudiaron en centros educativos costarricenses, sin embargo, al igual que Giovanni Durini, Lorenzo envió a sus hijos a estudiar artes a Italia, particularmente a Milán.

23 Si bien esta sociedad fue registrada legalmente en Costa Rica hasta la década de 1890, en el mausoleo de la familia Cruz Avendaño, ubicado en el Cementerio General de San José, encontramos la inscripción: Durini. Hermanos_Genova. 1887. 
pues se hicieron con un buen número de contratos relativos a este ambicioso proyecto estatal (Oviedo \& Santamaría, 2015, pp. 14-18).

De modo paralelo a su éxito como artista y contratista, Lorenzo estableció amistad con el militar ecuatoriano Leónidas Plaza Gutiérrez, quien se encontraba exiliado en Costa Rica por motivos políticos (Capello, 2012, p. 124). Tras cambios en la política ecuatoriana, Plaza regresa a su país a mediados de la década de 1890 y, en 1901, asciende a la presidencia de la República. Como parte de los principales objetivos de su mandato, Plaza quería invertir en la construcción de calles, edificios y monumentos relacionados con determinado programa ideológico; para lo cual contactó a los hermanos Durini (Capello, 2012, p. 124).

Francesco y Lorenzo llegaron a Quito, en 1902 y 1903 respectivamente. En dicha ciudad, no solo produjeron una gran cantidad de obras de carácter público y privado, sino que se instalaron permanentemente. Allí Lorenzo estableció la sociedad Durini e Hijos, constituida por él y sus hijos Pedro y Francisco Manuel Durini Cáceres, desde la cual fueron coordinados y ejecutados importantes proyectos, mayoritariamente para el Estado ecuatoriano. Sin embargo, al presente estudio no le compete la producción duriniana en Ecuador, pues nuestro análisis estilístico se concentrará en una obra arquitectónica correspondiente a su período en Costa Rica: las Casas de Corrección de Menores (1897-1902).

Tras contextualizar la situación socioeconómica del Reino de Italia, la postura oficial del Estado costarricense ante las inmigraciones de europeos y una vez expuesta sucintamente la historia de la familia Durini, a continuación presentaremos un caso de estudio en el que podemos corroborar la relevancia que la migración europea, especialmente italiana, y en este caso la de los Durini, tuvo en la transformación cultural del país.

\section{Las Casas de Corrección como caso de estudio}

Antes de referirnos al proyecto de las Casas de Corrección, nos parece pertinente contextualizar brevemente cuáles eran los lenguajes arquitectónicos predominantes en el país, durante la segunda mitad del siglo XIX. En el caso de la arquitectura producida por el Estado costarricense, no podemos referirnos a un lenguaje principal, sino a varios estilos derivados de un modelo de carácter académico e inspirado en distintos historicismos. Desde su creación en 1860, la Dirección General de Obras Públicas se sirvió de un lenguaje arquitectónico académico-historicista inclinado principalmente hacia el neogriego, el neoclasicismo, el neorenacimiento y el neopalladianismo. Edificios como el Teatro Mora (1850), el Palacio Nacional (1851-1856), la Universidad de Santo Tomás (1854-1868) y la primera sede del colegio San Luis Gonzaga (1856-1870), son ejemplos de los lenguajes arquitectónicos antes señalados (Sanou, 1998, pp. 32-34; Sanou \& Quesada, 1998, pp. 158-177). 
Durante el último cuarto del siglo XIX e inicios del XX la arquitectura oficial se diversificó en cuanto a lenguajes y técnicas constructivas, tal fenómeno se debió principalmente a la consolidación de un Estado autoritario y progresista, en el sentido positivista. Si bien el Estado había financiado la construcción de iglesias católicas, centros educativos y edificios de carácter bélico durante el período 1848-1870, fue a partir de la dictadura del general Tomás Guardia Gutiérrez que la República varió significativamente su paisaje arquitectónico de la mano del orden y del progreso (Quesada, 2007; Sanou \& Quesada, 2008, p. 220-221). En el clímax de este período se diseñó y construyó un edificio que retomó los lenguajes trabajados desde mediados de siglo XIX, pero que se proyectó a partir de su monumentalidad y la riqueza de sus materiales como un ícono del progreso alcanzado por Costa Rica: el Teatro Nacional24.

Ahora bien, en relación con la diversificación estilística mencionada, orientándonos hacia nuestro caso de estudio, encontramos una significativa influencia del neorrománico y el neogótico, principalmente para el diseño de cuarteles, centros penales, hospitales, hospicios y mausoleos (Altezor, 1986, pp. 64-70; Sanou \& Quesada, 1998, pp. 242-257)25. No obstante, debe aclararse que las tendencias medievalistas se incorporaron a un modelo de raíz neoclasicista, es decir, dichos lenguajes conviven en diversos edificios. Si bien la influencia del neogótico es evidente principalmente en construcciones religiosas, en la arquitectura civil también se emplearon rasgos ojivales (Sanou \& Quesada, pp. 261-269); esta relación estilística se asemeja al proceso de adaptación del estilo arquitectónico neoclasicista en diversas iglesias edificadas décadas atrás (Sanou, 1998, pp. 36-41).

Durante las dos administraciones (1894-1898 y 1898-1902) del presidente Rafael Iglesias Castro (1861-1924), se crea el proyecto para la formulación de una "Ciudadela de Policía", donde estarían contempladas Casas de Corrección, cárceles o penitenciarías y edificios destinados a la detención de vagos (Ulloa, 1897b, p. XXIV; Zamora y López, 1988, p. 27). Hasta donde se ha podido constatar dicha "Ciudadela" no llegó a concretarse, salvo las Casas de Corrección. El 27 de abril de 1897 ya estaba contratado el arquitecto Lorenzo Durini para el diseño y producción de las Casas, y pocos días después dio inició la construcción que quedó terminada en 1902.

Para entonces, el arquitecto Francesco Tenca trabajaba para Lorenzo Durini. Aunque, historiográficamente el diseño ha sido atribuido a Tenca (Sanou \&

24 Además, la ruta de desarrollo económico trazada por los liberales permitió que diversas empresas, nacionales e internacionales, tuviesen el capital necesario para introducir al paisaje costarricense, principalmente al josefino, edificios con estilos distintos a los promulgados por el Estado. En dichas construcciones de carácter privado se ejecutaron diseños en los cuales la copiosa combinación de estilos, vinculada con los lenguajes modernos, genera un lenguaje ecléctico (Altezor, pp. 71-85). El edificio de Correos y telégrafos de Costa Rica (1914-1917) es una muestra del eclecticismo al servicio del Estado.

25 En este sentido, hay una similitud con el uso del estilo gótico y normando (románico) en prisiones, al momento de ver los edificios penales elaborados en Inglaterra desde finales del siglo XVIII, y durante el siglo XIX (Pevsner, 1980, p. 200). 
Quesada, 1998, p. 237; Fernández, 2013, p. 43), no se ha encontrado evidencia documental que corrobore dicha hipótesis. La autoría principal de Lorenzo queda constatada en la Declaratoria de Patrimonio Nacional, publicada en La Gaceta no. 229, el lunes 30 de noviembre de 1981 (Zamora y López, 1988, p. 157) y en este caso sí es posible respaldar tal aseveración con una serie de documentos. En el protocolo notarial elaborado por Jesús Marcelino Pacheco Gutiérrez el 15 de diciembre de 1896, relativo al contrato de servicios entre Durini y Tenca, se expone que:

El señor Tenca se compromete, en su calidad de arquitecto, a ser fiel empleado del señor Durini: se hará cargo de la parte técnica y de la administración y dirección de todos los trabajos que dicho señor le encomiende, levantará los planos, hará los presupuestos y manejará los obreros que el señor Durini le encomiende, ya sea que dichos trabajos se ejecuten por cuenta propia del señor Durini, ya por cuanta de la Casa "Durini Hermanos", de este domicilio, de la cual es socio gerente el mencionado Don Lorenzo (Archivo Nacional de Costa Rica, 15 de diciembre de 1896, fol 7f).

Este convenio tenía duración hasta el 31 de diciembre de 1898 y durante el tiempo que estuviese vigente, Francesco Tenca no tenía permitido prestar sus servicios sin el consentimiento de Lorenzo (Archivo Nacional de Costa Rica, 15 de diciembre de 1896, fol 7f). Esto quiere decir que al momento de ser contratados para las Casas, Tenca estaba como empleado de Lorenzo Durini. A esta evidencia se suma la formación de una sociedad industrial colectiva entre Durini y Tenca, creada el 24 de febrero de 1899, ante el notario Manuel Bejarano Solano. Esta sociedad tendría la duración de dos años, contando desde el $1^{\circ}$ de enero de 1899. En el protocolo notarial dice que:

El socio Durini es el gerente de la Compañía y el único que hará uso de la forma social... Durini en su calidad de gerente hará todos los negocios de la Sociedad. Tenca se hará cargo de la parte técnica y dirección de los trabajos que el gerente le encomendó, y levantará los planos y presupuestos de las obras (Archivo Nacional de Costa Rica, 24 de febrero de 1899, fol. 50f).

De la cita anterior, debemos puntualizar que Durini haría los negocios de la Sociedad, ya que en efecto, en cuanto a las Casas de Corrección, era Lorenzo quien se comunicaba con la Secretaría de Fomento. En la Memoria de Fomento presentada al congreso constitucional de 1897, aparece el contrato celebrado el 27 de abril entre Ángel Miguel Velázquez ${ }^{26}$, Director General de Obras Públicas y Lorenzo Durini, en el que se convenía que:

26 Ángel Miguel Velázquez se formó en la ciudad norteamericana de Nueva York y en el Reino de Italia (González, 1921, p. 291; Sanou, 1998, p. 38; Quesada, 2007, p. 63). Este ingeniero mexicano introdujo en Costa Rica las técnicas constructivas que se enseñaban en Estados Unidos y en Europa durante las década de 1850. La gestión de Velázquez como director de la Dirección General de Obras Públicas, en el período 1866-1869, representó la consolidación de las tipologías historicistas de estilo neogriego y neorrenacentista como los lenguajes oficiales del Estado (Sanou, 1998, pp. 3441; Sanou \& Quesada, 1998, pp. 151-217). 
Durini se compromete á construir los edificios del Proyecto Casa de Corrección de menores, sujetándose en cuanto á distribución y dimensiones al proyecto formado por la Dirección General de Obras Públicas, y en cuanto á la arquitectura de la parte exterior de los mismos edificios, al proyecto presentado por Durini y aprobado por esta Dirección (Durini y Velázquez en Ulloa, 1897a, p. 158).

Hasta el momento no tenemos certeza de que el diseño del edificio sea totalmente autoría de Lorenzo Durini. No obstante, las fuentes nos muestran que quien estaba a cargo era el propio Lorenzo, es decir, Tenca pudo haber tenido alguna intervención en el diseño arquitectónico, pero las decisiones eran tomadas por Lorenzo ${ }^{27}$.

Entonces, los arquitectos Durini tenían a su cargo la construcción de dos edificios gemelos principales, uno destinado para los hombres y otro para las mujeres. En el caso de la Casa de Corrección para los hombres se construiría un taller de maquinaria y en la Casa para mujeres, un lavandero y un taller de aplanchado. Se suman a este diseño dos edificios más, de menor tamaño, destinados a la administración. El inmueble para hombres estaba por terminarse en 1899, mientras que el de las mujeres se encontraba en un estado avanzado. Hacia 1902 los trabajos se habían concluido, pero la función original que iban a tener las Casas de Corrección queda desplazada y se destinan los edificios a ser las nuevas instalaciones del Liceo de Costa Rica ${ }^{28}$ en 1903 (Zamora y López, 1988, pp. 28-29).

Cabe aclarar que este artículo no se enfoca, propiamente, en la historia del Liceo, ya que el diseño y función de los edificios no estaban contemplados para el mismo. De acuerdo con lo que vamos a exponer a continuación, por motivo de que los trabajos no habían sido realizados para albergar dicha institución, podemos suponer que: si se hubiese hecho un contrato entre el Estado y los arquitectos Durini y Tenca para la construcción del Liceo de Costa Rica, lo más seguro es que hubiesen pensado en un diseño distinto al proyectado aquí29.

Ahora bien, ¿cuál era la idea original para el estilo de las Casas de Corrección, y cómo esta empataba en las políticas progresistas y modernistas que el Estado estaba elaborando? Tenemos conocimiento de una carta elaborada

27 Inclusive en el ámbito social, la construcción era atribuida a Durini. Por ejemplo, en una nota anónima titulada "ITALIA RIDENTA", publicada el 12 de diciembre de 1897 en El Heraldo de Costa Rica, Lorenzo aparece como aquel a quien el Gobierno decidió "encomendarle directamente - la construcción magna de las Casas de Corrección" (p. 2).

28 Fundado en 1887 gracias a la reforma educativa de don Mauro Fernández. Las primeras instalaciones son el resultado de la unión de la Escuela Modelo y de la Escuela Normal, construidas un año antes (Zamora y López, 1988, p. 17).

29 Las razones para utilizar las Casas de Corrección para el Liceo de Costa Rica se muestran en la Memoria de Instrucción Pública Presentada al Congreso Constitucional (1902-1903), publicada en 1903, donde Leónidas Pacheco, Secretario de Estado en el despacho de Instrucción Pública, expresa: "Invertida por la Nación una enorme suma en la construcción de las Casas de Corrección de Menores, é imposibilitado el Gobierno para dedicarlas á su primitivo objeto por las cuantiosas sumas que ello hubiera demandado, hubo de buscársele destino á los costosos edificios, puestos por medio de reparaciones urgentes en estado de servir. Nada más natural que destinarlos á la segunda enseñanza" (Pacheco, 1903, pp. VII-VIII). 
por Lorenzo Durini dirigida al señor Secretario de Estado en el Despacho de Fomento, fechada el 7 de mayo de 1898. Esta carta es fundamental ya que problematiza el estilo arquitectónico de las Casas, y nos da una pequeña muestra de la forma de proceder de Lorenzo a la hora de diseñar una construcción. Durini pone como ejemplo la Casa de Corrección para hombres, que como bien expusimos anteriormente, estaba mucho más adelantada que la de mujeres. El arquitecto escribió en relación con los frentes de la construcción que estos eran de un estilo bizantino y explica las razones por las cuales este fue elegido:

La imponente y severa majestad de edificios construidos en la Edad Media, en que domina el estilo bizantino, tales como la Basílica de San Marcos en Venecia, la Catedral de Moscow y otros muchos, que ponen en evidencia el carácter fiero de la época feudal, dejan ver lo apropiado que es para construcciones destinadas al objeto que tienen las Casas de Corrección. Las líneas puras de este estilo, las curvas de ornamentación y los detalles más insignificantes revelan energía y severidad, a la par que belleza estética (Durini en Zamora y López, 1988, p. 154).

Hay varios elementos clave dentro de este párrafo. Primero debemos observar que en el proceso de diseño de una edificación, Lorenzo tomaba en cuenta la función del edificio, eso determinaría el estilo, lo que le da un carácter historicista a sus creaciones. Esto nos permite decir que Durini no aplicaba libremente los estilos, o que se sometía completamente a alguna exigencia de gusto por parte del Estado; sus obras estaban fundamentadas, el estilo por lo tanto es simbólico y coherente con la finalidad del inmueble ${ }^{30}$. Si tomamos en consideración esto, podemos ver con nuevos ojos los trabajos producidos por Lorenzo en el país, en donde no hay nada deliberado, el motivo y el tema de la obra están en armonía en la cabeza del arquitecto y, como veremos más adelante, estos se logran complementar perfectamente con las ideas que se estaban proyectando en el momento.

Debemos además señalar ciertas palabras importantes del párrafo, que no han de olvidarse. Las nociones histórico-estéticas medioevales de imponencia, severa majestad y carácter fiero por las que el arquitecto apela es lo más importante en la construcción. Estos rasgos van de acuerdo con la finalidad de elaborar un inmueble para el trato con menores que han caído en la delincuencia. El edificio debía imponerse ante sus habitantes, tenía que ser una ayuda visual para las políticas educativas y correccionales que se iban a aplicar dentro del edificio y, por ello, cito nuevamente, "las líneas puras de este estilo, las curvas de orna-

30 Esto empata en cierta medida con las propuestas teóricas del famoso arquitecto italiano Camillo Boito (1836-1914), una de las mayores influencias de enseñanza de la arquitectura en Italia a finales del siglo XIX (Godfrey, 2005, pp. 43-45; Kirk, 2005, p. 179). En principio, la posibilidad de que Lorenzo y Francisco conociesen las teorías de Boito no era factible. Boito se dedicó a la enseñanza en la Academia de Brera, Milán, desde 1860; y fue aquí donde logró influenciar disímiles tratados referentes a cómo crear una arquitectura italiana que reflejara al reino unificado. Como vimos en el primer capítulo, Lorenzo y Francisco fueron enviados por su padre a estudiar a Génova; si se toma en cuenta la fecha nacimiento de Lorenzo (1855), supondríamos que la década en la que realizaron sus estudios sería la década de 1870, por lo que la posibilidad de que tuviesen algún contacto con Boito no puede ser descartada del todo. 
mentación y detalles más insignificantes revelan energía y severidad". Entonces, el estilo se vuelve el "apropiado" y por lo tanto funcional, lo que explica la gran diferencia estilística entre este trabajo y lo elaborado por los hermanos Durini en cuanto a marmolería en el Teatro Nacional.

El conflicto de la propuesta de Lorenzo surge cuando habla de un estilo bizantino y hace referencia a la Basílica de San Marcos, en Venecia y a la Catedral de Moscú. Si bien estos trabajos podían ayudarle a explicar las nociones de severidad, imponencia y majestuosidad, estilísticamente hablando difieren bastante de lo elaborado por el italo-suizo ${ }^{31}$. Aun si buscamos otros modelos bizantinos para comparar las Casas, el trabajo en encontrar similitudes se vuelve mucho más arduo. A continuación, explicaremos cómo se compone la fachada de los edificios, para ello nos serviremos de una impresión azul de la fachada de la Casa de Corrección para hombres (Ilustración 3). Esta imagen es la más clara que poseemos para entender cómo era el edificio en sus orígenes ${ }^{32}$.

La fachada se puede descomponer en líneas generales en tres partes: la bahía central y las dos alas laterales. Estas últimas estructuras son más grandes que la entrada principal y rematan sus fachadas con hastiales, carentes de ornamentación, los cuales contienen un óculo u ojo de buey. Exceptuando la ventana central, las ventanas de medio punto del segundo piso están enmarcadas en la parte superior con arcos sutilmente apuntados, elaborados con dovelas de dos colores distintos que se alternan. Esta es la única decoración que contienen las partes laterales del segundo piso del edificio, lo cual le da sobriedad a la fachada. En el caso de las ventanas de medio punto del primer piso, la dovela central es una clave de mayor tamaño y no termina con el diseño apuntado de las del segundo. Asimismo el primer piso está almohadillado, al estilo de la arquitectura Renacentista, evidente en trabajos como el Palacio Medici-Riccardi, Florencia. De acuerdo con Durini, las formas de las ventanas, las formas de los arcos y la selección de sus colores, en conjunto con el basamento de piedra del primer piso y el color destinado a los muros, hacía que la obra estuviese en armonía y demostrase solidez (citado en Zamora y López, 1988, p. 154). La bahía central se diferencia en su composición al resto del edificio, lo que la hace sobresalir del resto. En este caso no se ha almohadillado el primer piso, sino que se han unificado la composición de colores con su parte superior, colores que lo más seguro fuesen los mismos a los introducidos en los arcos y en los marcos de los óculos.

31 A diferencia del diseño de las Casas de Corrección, encontramos durante el primer cuarto del siglo XX la basílica de Nuestra Señora de los Ángeles (1912-1924), un ejemplar del historicismo neobizantino. estaban destinadas a ser sede del Liceo de Costa Rica. 


\section{(c) $\underset{\mathrm{BY}}{(\mathrm{FC})}$}

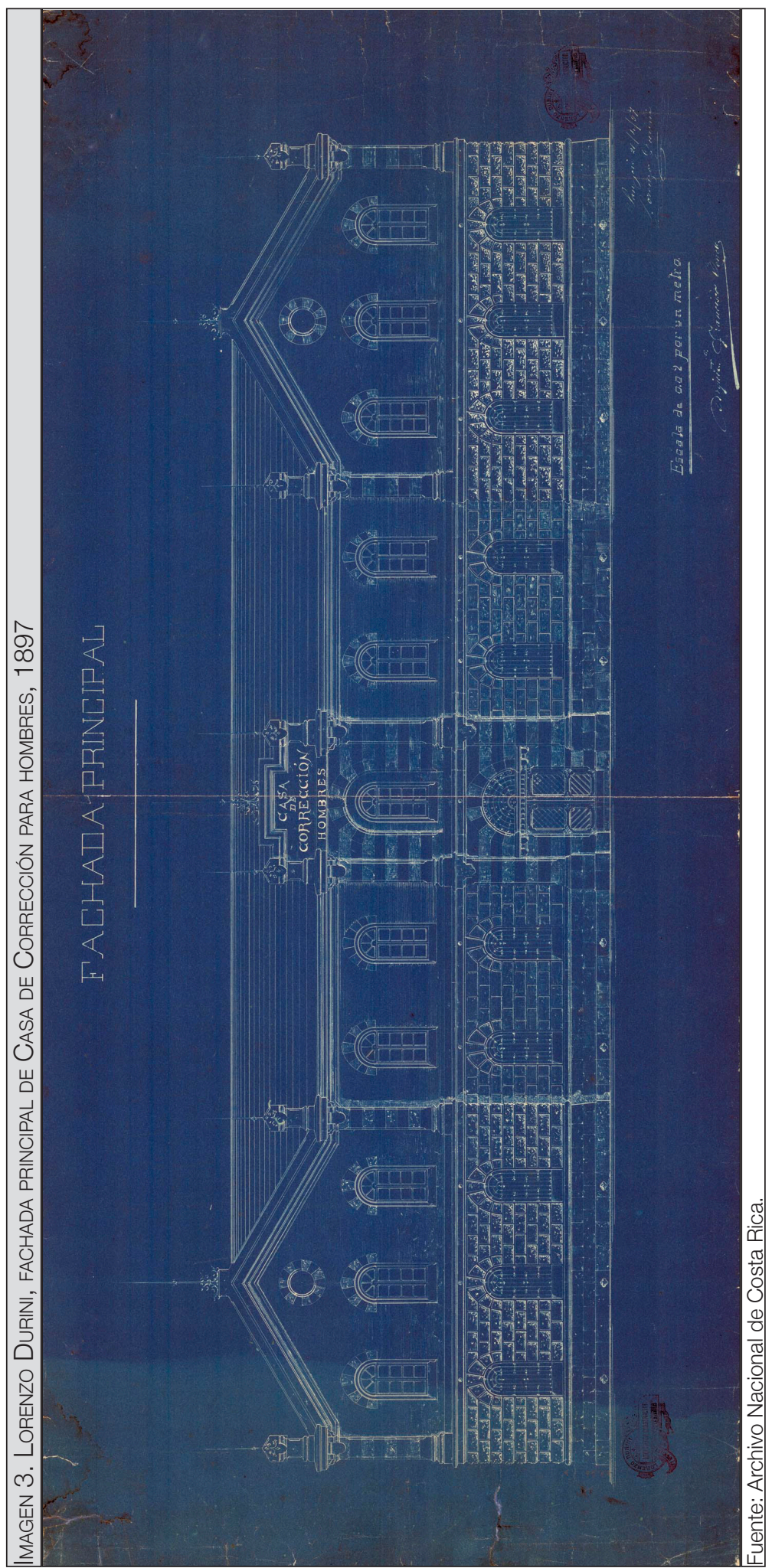


Asimismo la parte superior de la bahía termina en una especie de hastial escalonado ${ }^{33}$.

Con esta breve descripción empezamos a dudar de a qué se refiere Lorenzo cuando habla de un estilo bizantino. Podríamos suponer que, en este caso, Lorenzo está haciendo referencia a un "estilo Medioeval", que significa severidad, imponencia y majestuosidad, y que a partir de ello empezó a trabajar en darle a la construcción una fachada regia y acorde con su funcionalidad. La sobriedad del segundo piso, con los hastiales laterales, y la inclusión de óculos nos recuerdan la arquitectura románica, especialmente, al Primer Románico o Románico Lombardo. Asimismo, la composición general de la fachada ya tiene antecedentes en la misma época, como es posible visualizar en el Hospital de Gallarate, ubicado en Varese, Italia, realizado por el arquitecto italiano Camillo Boito ${ }^{34}$, elaborado hacia 1870 (Ilustración 4). Así, si tratamos de encontrar la influencia de la arquitectura de Bizancio en Italia, nos remitimos directamente a Venecia, ya de por sí mencionada por Durini con la Basílica, y lo que encontramos que puede resultar influyente es lo que hoy conocemos como el estilo Gótico Veneciano, en donde confluyen el arco apuntado gótico con la arquitectura bizantina y la morisca. Claros ejemplos residen en el Palacio Cavalli-Franchetti y el Palacio Ducal de Venecia. Son notables además ciertas similitudes que van en concordancia con el revival del Gótico Veneciano acontecido en el siglo XIX,

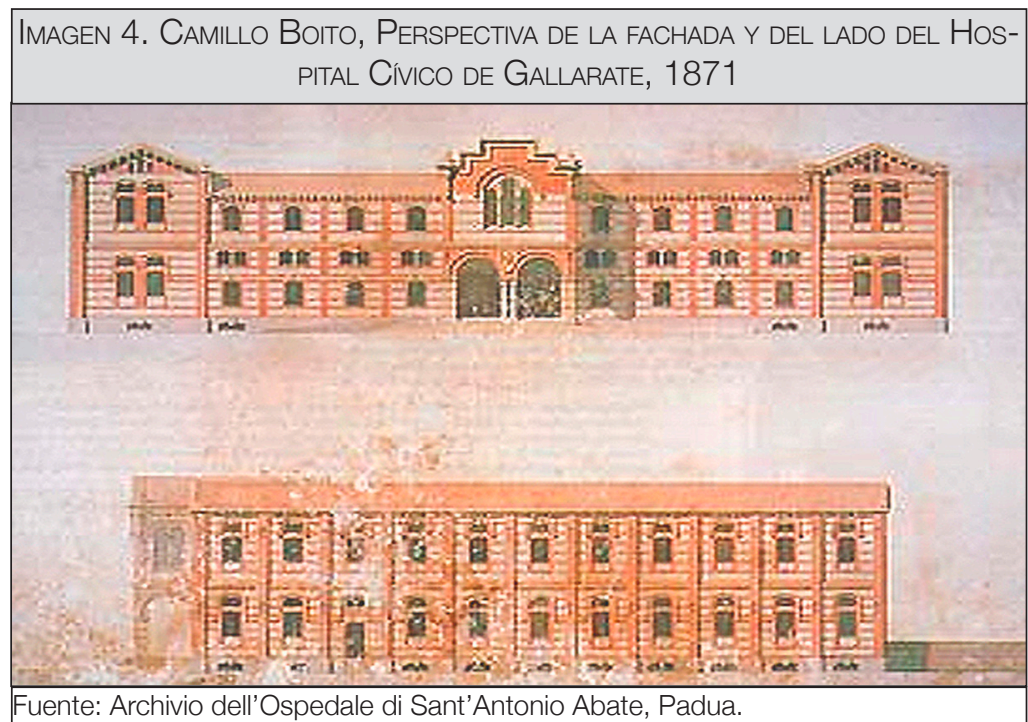

33 Contamos con una fotografía tomada hacia 1930, donde aparece una serie de cambios en el diseño inicial, sobre todo en el segundo piso, donde los arcos sutilmente apuntados que enmarcan las ventanas ya no existen y la continuidad estilística de la bahía central que venía desde el primer piso también ha sido eliminada. A su vez, los hastiales laterales se convierten aquí en frontones, ricamente ornamentados y delimitados con una cornisa horizontal. Hasta el momento no tenemos conocimiento de cuándo fueron realizados estos cambios. 
como el Memorial Hall, ubicado en Manchester o la Academia Nacional de Dibujo de Estados Unidos, Nueva York (llustración 5).

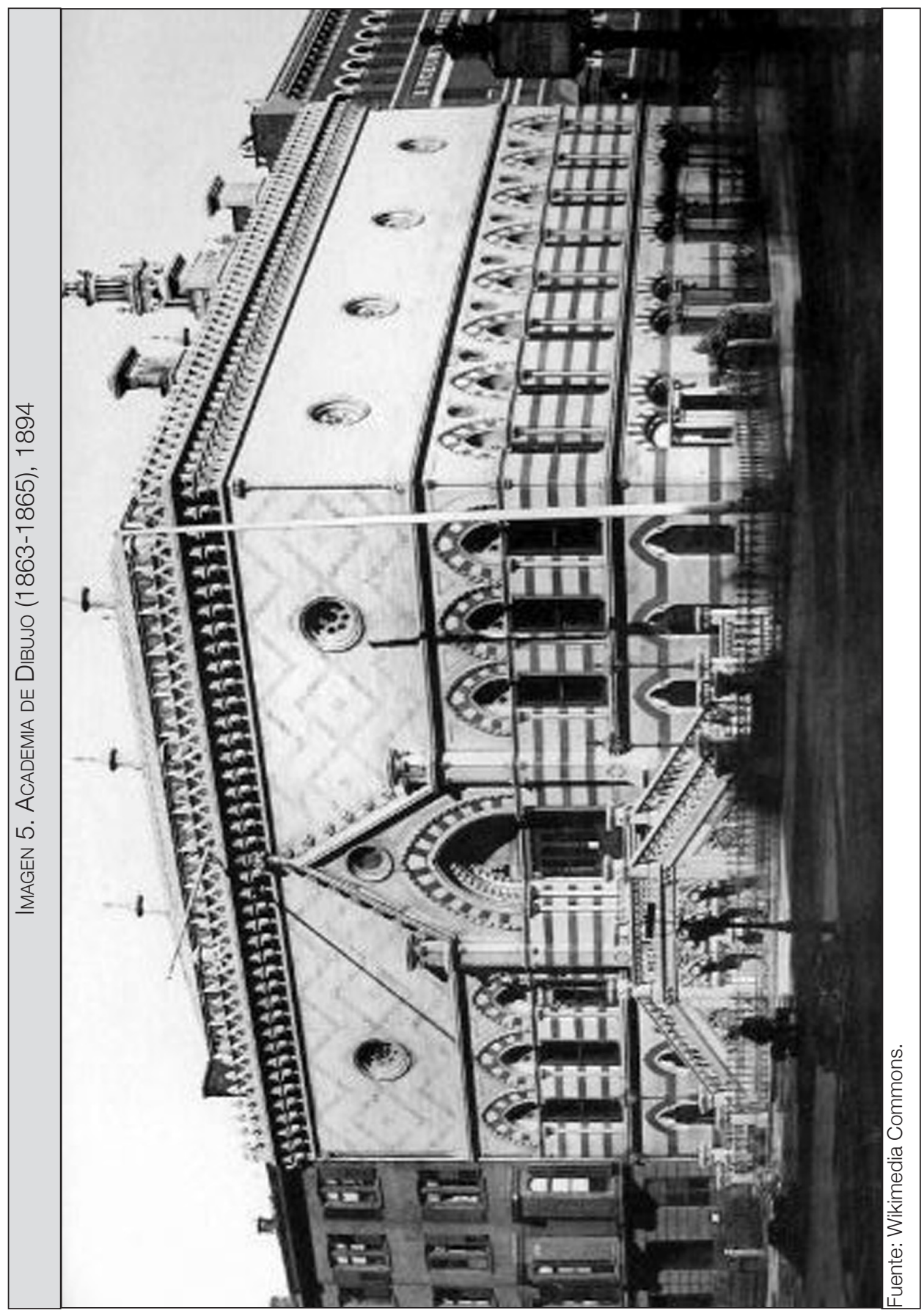


A su vez, con la combinación de ladrillos en el segundo piso que forman los arcos apuntados que decoran las ventanas de medio punto, vemos una vez más la mezcla de lo bizantino, gótico y morisco, tal como se explaya en el revival de la arquitectura Bizantina que sucede en Bristol, como se confirma en el Granary, construido en 1869 por Achibald Ponton y William Venn Gough. Tal como lo manifestamos en la descripción del edificio, el artista se sirve de la tendencia renacentista en almohadillar el primer piso de la estructura ${ }^{35}$.

En definitiva, partiendo de estas ideas, podemos decir con certeza que estamos frente a un estilo historicista en su máxima expresión, el cual utilizó de base la Edad Media y que se sirvió del concepto "estilo bizantino" para referirse a trabajos arquitectónicos cuya severidad y disposición regia estuviesen en función de la finalidad del edificio. Si tomamos en cuenta el historicismo de Lorenzo, no tenemos por qué buscar en la estructura aquí tratada un sometimiento estilístico fiel a la arquitectura bizantina. Esta afirmación la exponemos a partir de que los mismos revivals que llegan a suceder en el siglo XIX no son reproducciones fieles de las bases histórico-estilísticas que están tratando, sino que toman los estilos como referentes fundamentales para nuevas composiciones. Con la alusión al revival del Gótico Veneciano y al revival de la arquitectura bizantina en Bristol, dejamos clara la utilización de la historia de la arquitectura en función de producir trabajos que satisfagan las nuevas necesidades de la sociedad y que estén acordes con el desarrollo de las nuevas tecnologías y la industria.

El trabajo de Lorenzo, finalmente, lograba empatar con las políticas que el Estado promulgaba. Su justificación Bizantina (Medieval) estaba en línea con las ideas que habían proyectado la creación de las Casas. Bajo su función original, las Casas de Corrección de Menores cumplían un papel fundamental dentro del programa intelectual de la época regido por las nociones de progreso positivo que imperaban. José Astúa Aguilar, Secretario de Estado en el Despacho de Fomento, lo dice con claridad en la Memoria de Fomento presentada al Congreso Constitucional de 1899:

Debe el país complacerse en realizar su loable proyecto de asilo para los menores que el vicio y el crimen reclutan, robándolos al progreso de la cultura y de la riqueza patrias, para convertirlos en enemigos del bien, en perturbadores del hombre trabajador y probo y amenaza de la sociedad, por que en esta función precautoria de la degeneración moral, que es la más grave enfermedad de un pueblo, cumple el Estado el más premioso de sus deberes y realiza el Derecho su mejor conquista (Astúa, 1899, p. XVIII).

La Casa de Corrección, con su estilo "medieval", se volvía la herramienta perfecta para tomar a estos "menores que el vicio y el crimen reclutan" y reivindicarlos. La Casa era un lugar de rectificación, por lo tanto, su forma debía de tener una severidad estética. En línea con esto podemos mencionar las

35 Elemento también presente en el Teatro Nacional de Costa Rica. 
preocupaciones existentes respecto de la correcta funcionalidad del edificio, expresadas por Ricardo Pacheco, el Secretario de Estado en el despacho de Gobernación, en la Memoria de Fomento presentada al Congreso Constitucional de 1900:

Se preocupa el gobierno en estudiar la organización, régimen y sistema administrativo que allí deben implantarse, para asegurar buen éxito á la moralizadora y humanitaria tarea que allí habrá de realizarse con la regeneración de los que por su edad están en aptitud de ser útlies á la sociedad y á su patria; y al cumplimiento del deber en que se encuentra el Estado de estorbar, por todo medio, la propagación del vicio, librando á la juventud honrada del contacto de aquellos cuyo ejemplo puede corromperla (Pacheco, 1900, p. XIV).

La importancia que tenía el edificio para la transformación urbana de San José es clara. Como bien apunta la historiadora Florencia Quesada Avendaño, en su tesis doctoral La modernización entre cafetales: San José, Costa Rica, 1880-1930, para finales del siglo XIX el concepto de progreso amalgamaba la tecnología e industria con el cambio arquitectónico que se estaba llevando a cabo en la capital. Debemos tener claro que el paisaje urbano capitalino no tenía una mera función estética, sino que era un elemento fundamental para la consideración de San José como una ciudad "progresiva" (Quesada, 2007, p. 80). Con esto la autora se refiere a una importante publicación del Diario de Costa Rica, del 21 de octubre de $1897^{36}$, aproximadamente seis meses después de que se diera inicio a la construcción de las Casas de Corrección y en donde se expone a las mismas como componentes del progreso y la civilización:

Se abre por todas partes camino el carro del progreso y de la civilización y no puede ser de otra manera. Aquí en esta nuestra San José vence por todas partes sus huellas. Si no que lo diga el Teatro, el Hipódromo, La Casa de Corrección, la Barbería de Pedro Muñoz y la Pacata de los hermanos Panisk; establecimientos montados al estilo europeo (Diario de Costa Rica, 21 de octubre de 1897, p. 3).

Con lo dicho hasta aquí, podemos decir que las Casas de Corrección de Durini revelan la importancia de la presencia del suizo-italiano en nuestro país, por motivo de que logró alinear su formación arquitectónica con los objetivos que se estaban persiguiendo en el programa político de la nación. El estilo de las Casas de Corrección se logra justificar por medio de la función de las mismas, las cuales se volvían organismos fundamentales para rectificar a un grupo específico pero esencial para el progreso de la sociedad y, por lo tanto, para el país. De esta forma, los edificios de Lorenzo se convierten en un componente principal dentro de la transformación urbana josefina dirigida a la concepción de una Costa Rica progresiva y civilizada.

36 Día de la inauguración oficial del Teatro Nacional de Costa Rica. 


\section{Conclusiones}

A partir de lo desarrollado en este trabajo, podemos plantear una serie de afirmaciones relativas a la migración cultural italiana que aconteció en Costa Rica, específicamente, en relación con el caso de los hermanos Durini. Sabemos que Costa Rica promovió con fuerza la inmigración de europeos en las últimas décadas del siglo XIX, esto empató con el contexto socioeconómico que vivía el recién creado Reino Unido de Italia, cuya inestabilidad interna unida a la Gran Depresión de 1873-1896 propició la migración de una parte importante de la población; de hecho, en conformidad con Bariatti, solamente entre 18871888 la inmigración a Costa Rica fue aproximadamente de 1500 personas (2001, p. 71). El interés del Estado costarricense residía tanto en la exigencia de mano de obra, como en la llegada de programas intelectuales-culturales internacionales (europeos), los cuales eran percibidos como los adecuados para el proceso de modernización y civilización de la nación.

Estas políticas, por supuesto, fueron aprovechadas por una cierta clase de inmigrantes, como lo fue el caso de los hermanos Durini, originarios de Tremona, Italia, cuya formación artística se llevó a cabo principalmente en Génova, quienes a través de varias estadías en las que está involucrado el continente americano (Tremona - Perú - Génova - Guatemala - El Salvador - Honduras - Nicaragua - Costa Rica - Ecuador, entre otros), lograron crear una red internacional de comercio artístico, cuyo entramado todavía estamos intentando descifrar. Con la posible llegada de Francesco Durini a Costa Rica, en 1886, se marcó el inicio de una serie de relaciones entre los hermanos y el Estado costarricense. Pareciera que Lorenzo y Francesco Durini entendían perfectamente qué tipo de vínculos y ofertas debían de realizar, ya que su participación en la modernización del país fue constante. Asimismo, establecemos como hipótesis que la formación artística de los hermanos, principalmente en arquitectura, lograba entrar en armonía con el programa intelectual que proponía el gobierno. Esta hipótesis será objeto de un ulterior estudio, ya que no tenemos todavía claridad acerca de cuáles fueron los estudios realizados por los hermanos en Génova así como cuales fueron sus vinculaciones en el ambiente artístico y arquitectónico que se estaba desarrollando en la segunda mitad del siglo XIX en Italia.

Como resultado del estudio del proyecto de las Casas de Corrección para hombres y mujeres concluimos, a través de un análisis tanto formal como de contenido, que Lorenzo Durini no estaba realizando una venta deliberada de cultura europea que satisficiese los gustos e intereses del Estado. Esto quiere decir que Lorenzo, en calidad de comerciante y arquitecto, vendía diseños arquitectónicos con base en una serie de contenidos justificados a través de la corriente historicista, lo que implicaba que el italo-suizo no estaba necesariamente sometido a cualquier exigencia estética gubernamental, sino que en primera instancia hacía una propuesta específica en función de lo que le 
estuviesen solicitando ${ }^{37}$. Los vínculos entre la estética como elemento simbólico de la función del inmueble y las políticas de progreso del país se componen aquí como un esfuerzo premeditado entre las dos partes. Podemos establecer como hipótesis que existía un compromiso por parte de Lorenzo de crear una arquitectura que pudiese justificarse estética y funcionalmente, y para ello se sirvió de un historicismo arquitectónico sin precedentes en el país. Las Casas de Corrección entraban en armonía con su objetivo original $y$, en conformidad con disímiles fuentes primarias de la época, vemos que ciertamente se convertían en un elemento ineludible a la hora de hablar del "carro del progreso y civilización" que estaba recorriendo San José a finales del siglo XIX.

En conclusión, a través de las Casas de Corrección atribuidas, principalmente, a Lorenzo Durini Vasalli, podemos corroborar en gran medida la importancia que tuvieron los hermanos Durini para la transformación del paisaje urbano en Costa Rica, sobre todo de San José, considerada como la ciudad que llevaba la punta de lanza del progreso, del orden y de la civilización dentro del país. De esta forma los Durini se vuelven un caso ejemplar de las intenciones del Estado en promover políticas de migración europea a finales del siglo XIX, para la transformación positiva cultural de la nación.

\section{Referencias}

Altezor Fuentes, Carlos. (1986). Arquitectura urbana en Costa Rica: exploración histórica 1900-1950. Cartago: Editorial Tecnológico de Costa Rica.

Alvarado Induni, Guillermo Enrique \& Alvarado Induni, Carlos. (2008). Los Induni: orígenes de una familia de emigrantes suizos y su contribución a la imaginería, ornamentación y arquitectura en Costa Rica y Panamá (19082008). San José: Editorial Librería Alma Máter.

Archivo Nacional de Costa Rica. Planos y mapas. Costa Rica: Archivo Nacional de Costa Rica.

Archivo Nacional de Costa Rica. (15, diciembre, 1896). Protocolos Notariales [fuente Documental]. (Signatura 1015, fol 7f). Costa Rica.

Archivo Nacional de Costa Rica. (24, febrero, 1899). Protocolos Notariales [fuente Documental]. (Signatura 1122, fol 50f). Costa Rica.

Astúa, José. (1899). Memoria de Fomento presentada al Congreso Constitucional de 1899. San José: Tipografía Nacional.

37 Por supuesto, el proceso de construcción de la obra y las diversas conversaciones que tuviese el artista con el Estado, implicarían una serie de modificaciones al inmueble. 
Bariatti, Rita. (2001). Italianos en Costa Rica 1502-1952: de Cristóbal Colón a San Vito de Java. San José: Universidad Autónoma de Centro América.

Bienvenidos sean. (29 de enero de 1886). Otro Diario, p. 2.

Borsò, Vittoria; Temelli, Yasmin \& Karolin Viseneber (Eds.). (2012). Introducción: migraciones culturales - topografías transatlánticas. En México: migraciones culturales - topografías transatlánticas. Estudios sobre los itinerarios de las culturas. Frankfurt: Vervuert.

Capello, Ernesto. (2011). The Durini Cosmopolis: Crafting a Hyphenated Vernacular Architecture. City at the Center of the World: Space, History, and Modernity in Quito. Pittsburgh: University of Pittsburgh Press.

Cifuentes López, José Danilo. (2013). Las esculturas de la Avenida Reforma como medio de identidad histórica guatemalteca. (Tesis de Licenciatura). Universidad de San Carlos, Ciudad de Guatemala, Guatemala.

Crónica Josefina. (21 de octubre de 1897). Diario de Costa Rica, p. 3.

Del Pino Martínez, Inés. (2012). Los Durini: Artífices del rostro moderno de Quito. Análisis de la arquitectura en un marco socio-histórico. Quito (Inédito).

Fernández, Andrés. (2013). Los muros cuentan: crónicas sobre arquitectura histórica josefina. San José: Editorial Costa Rica.

Fischel, Astrid. (1992). El Teatro Nacional de Costa Rica: su historia. Costa Rica: Editorial Teatro Nacional.

Francisco A. Durini. (16 de noviembre de 1883). La Gaceta, p. 1103.

Francisco A. Durini. (19 y 26 de enero de 1885). Otro Diario, p. 4.

Garrido Torres, Lorena del Rocío. (2009). Registro, Inventario y Catalogación de los Mausoleos del Cementerio de San Diego (Tesis de Licenciatura en Restauración y Museología).

Godfrey, Sara. (2005). Patriotic Heterotopias: Architecture, City, and the Nation, Italy (1861-1911) (Tesis Doctoral). Londres: University College London.

González Flores, Luis Felipe. (1921). Historia de la influencia extranjera en el desenvolvimiento educacional y científico de Costa Rica. San José: Imprenta Nacional.

González Galeotti, Juana Victoria. (2006). La impronta italiana en las esculturas del Cementerio General de Guatemala (1881-1920). (Tesis de Licenciatura). $40 \quad$ Universidad de San Carlos, Ciudad de Guatemala, Guatemala. 
Gutiérrez Viñuales, Rodrigo. (1997). Presencia de Italia en la pintura y la escultura de los países sudamericanos durante el siglo XIX. En Artisti italiani in America latina. Presence, contatti, commerci. Roma: La Nuova Italia Scientifica.

Hobsbawn, Eric. (2010). La era del capital: 1848-1875. Buenos Aires: Paidós/ Crítica.

Hughes, Christopher. (2006). Ticino. A History of the Cantons. Unfinished and Unpublished. University of Kent. Recuperado de https://www.kent.ac.uk/politics/cfs/csp/pdf/09LTICINO.pdf

Inmigración. (6 de febrero de 1886). Otro Diario, p. 1.

Italia Ridenta. (12 de diciembre de 1897). El Heraldo de Costa Rica, p. 2.

Kirk, Terry. (2005). The Architecture of Modern Italy. New York: Princeton Architectural Press.

La inmigración. (24 de abril de 1890). La Prensa Libre, p. 2.

Oviedo Salazar, Mauricio \& Leonardo Santamaría Montero. (2015). Mercato Culturale: El nacimiento de la ornamentación de un Coliseo. Diálogos Revista Electrónica de Historia, 16(2).

Pacheco, Leónidas. (1903). Memoria de Instrucción Pública presentada al Congreso Constitucional (1902-1903). San José: Tipografía Nacional.

Pacheco, Ricardo. (1900). Memoria de Fomento presentada al Congreso Constitucional. Costa Rica: Tipografía Nacional.

Pevsner, Nikolaus. (1980). Historia de las Tipologías Arquitectónicas. BarceIona: Estudio Gili, S. A.

Progreso. Economía. Arte. (23 de mayo de 1889). La República, p. 1.

Quesada Avendaño, Florencia. (2007). La modernización entre cafetales. San José, Costa Rica, 1880-1930. Tesis del Doctorado en Estudios Latinoamericanos. Universidad de Helsinki, Finlandia.

Sanou Alfaro, Ofelia María. (1998). Arquitectura e historia en Costa Rica: templos parroquiales en el Valle Central, Grecia, San Ramón y Palmares (18601914) (Tesis de Maestría en Historia). Universidad de Costa Rica, San José, Costa Rica.

Sanou, Ofelia \& Quesada, Florencia. (1998). Herencia, ruptura y nuevas expresiones arquitectónicas (1841-1870); Orden, progreso y civilización (18711914). Transformaciones urbanas y arquitectónicas. En Elizabeth Fonseca y José Enrique Garnier (Eds.), Historia de la Arquitectura en Costa Rica. San José: Fundación Museos del Banco Central de Costa Rica. 
Silva, Gastón de. (1908). Párrafo de crónica. Páginas ilustradas, 5(204), p. 3456.

Torrejón Mora, José Vicente. (1997). Escultura monumental pública de Tegucigalpa. NORMA-ARTE, 17, 149-163.

Ulloa, Juan José. (1895). Memoria de Fomento presentada al Congreso Constitucional de 1895 por el Señor Secretario de Estado en esa cartera Dr. Don Juan J. Ulloa G. Costa Rica: Tipografía Nacional.

Ulloa, Juan José. (1897a). Memoria de Fomento presentada al Congreso Constitucional de 1897 por el Señor Secretario de Estado en esa cartera Dr. Don Juan J. Ulloa G. Costa Rica: Tipografía Nacional.

Ulloa, Juan José. (1897b). Memoria de Gobernación y Policía presentada al Congreso Constitucional de 1897 por el Señor Secretario de Estado en esas carteras Dr. Don Juan J. Ulloa G. Costa Rica: Tipografía Nacional.

Valdés Valle, Roberto Armando. (2010). Masones, liberales y ultramontanos salvadoreños: debate político y constitucional en algunas publicaciones impresas, durante la etapa final del proceso de secularización del Estado salvadoreño (1885-1886). Tesis de Doctorado en Filosofía Iberoamericana. El Salvador: Universidad Centroamericana José Simeón Cañas.

Velázquez, Carmela; Payne Iglesias, Elizet; Ungaro, Diego \& Silvia Meléndez Dobles. (2012). II nuovo mondo. La influencia cultural de los italianos en América. San José: Ambasciata d'Italia \& Universidad de Costa Rica.

Zamora, Carlos M. y López, Bernal. (1988). Liceo de Costa Rica. Un siglo de existencia. San José: Comisión Nacional de Conmemoraciones Históricas. 